\title{
ENTRE BLANCHOT Y KAFKA: MÁS ALLÁ DE LA LEY, EL SILENCIO
}

\author{
Sebastián Chun \\ Universidad de Buenos Aires \\ sebaschun@hotmail.com
}

\begin{abstract}
Resumen
Si buscamos un ideal de lenguaje que recorra toda la tradición filosófica, rápidamente nos encontramos con un paradigma lingüístico regido por el imperio de la lógica, cuya ley instaura el límite entre lo racional y el vacío silencio. Sin embargo, no podemos ignorar otra lógica que ha fisurado esa razón monolítica, abriendo la posibilidad de otro modo de pensar y también de pensar lo otro. Blanchot ha sido uno de los mayores exponentes de esta otra racionalidad, recibiendo una gran influencia de Kafka y acercando así su pensamiento a la literatura para así, quizá, pensar en el afuera.
\end{abstract}

Palabras Clave: lenguaje, literatura, lógica, escritura, subjetividad, utilidad.

\section{Abstract}

If we look for the ideal of language that goes through the philosophical tradition, we immediately find the linguistic paradigm ruled by the logical empire. This one sets the limit between reason and the meaningless silence. Nevertheless, we can't ignore the other logic that has fissured the monolithic rationality, opening the possibilities of other way of thinking and also thinking the other. Blanchot has been one of the most important exponents of that other reason and has received Kafka's great influence, so bringing his thought to literature perhaps made Blanchot think of the outside.

KEY WORDS: language, literature, logic, writing, subjectivity, utility.

\section{Introducción}

RA Con Aristóteles y el imperio de la voz, el silencio fue condenado a las oscuras y profundas tierras de lo imposible. El logocentrismo no solo ha excluido a la escritura no-fonética del mundo de la razón, sino que ha desterrado toda voz que no responda a la filiación con el logos, destinándola a la región del sin-sentido o la literatura, ambas muchas veces cercanas al mismo silencio. Los expulsados y su destino son una misma y única cosa: la locura es la ausencia de obra. Aristóteles fue el gran artífice de esta segregación lingüística en el mismo gesto por el cual instaura su propia habla como habla verdadera. Magia performativa y decisión soberana al mismo tiempo. Es en el libro IV de la Metafísica donde se establece la 
ley según la cual no existiría ningún camino transitable sin aceptar el principio de no-contradicción. Si alguien intentara rechazarlo, estaría condenado al silencio, o a un habla cercana al mismo, destinada al desvarío, a la errancia eterna, y a la soledad signo de la imposibilidad de todo diálogo ${ }^{1}$.

A pesar de la huella permanente que ha dejado la filosofía aristotélica con el paso de los siglos, en Sobre verdad y mentira en sentido extramoral, Nietzsche parece abrirnos hacia la posibilidad de lo imposible. Señala allí un ámbito que deja de lado la lógica tradicional, reconociendo al mismo tiempo que no existe un más allá de la misma, sino un movimiento de destrucción y estructuración constantes propio de la voluntad de poder; es decir, un recurrente jugar en los límites de la ley, en un movimiento que los trasciende y los vuelve a instaurar ${ }^{2}$. En este escrito, Nietzsche concibe al lenguaje como un conjunto de metáforas, entre las cuales algunas, una vez gastadas y sin fuerza sensible, se consideran verdades (Nietzsche 1990, p. 25). Entonces, esas verdades no son ajenas al plano de la no-verdad, sino tan solo un residuo al que se le ha otorgado el beneficio del olvido. De esta manera, para Nietzsche en el diálogo no se da un intercambio de significados unívocos, sino que el carácter mismo del lenguaje remite a la siempre imposible comunicación, ya que en su origen todo concepto es una metáfora y no un duplicado exacto del referente. Por lo tanto, el camino fundado en la ley aristotélica no es más que una brecha abierta y sustentada por convención o, más precisamente, por imposición de los más débiles. Ese significado único pretendido por el filósofo se desenmascara como una petrificación, una solidificación del devenir del mundo, que en última instancia oculta el carácter ambiguo del lenguaje, que siempre afirma el ser y el no ser. Luego, el camino intransitable del silencio, o del habla condenada a la soledad, sería el único digno de recorrerse para aquellos que todavía sueñan con afirmar la vida, y con ella, otro tipo de comunicación y, por qué no, de comunidad.

La pregunta que surge finalmente es: ¿cómo seguir hablando después de Nietzsche? Con Aristóteles, el habla fue condenada a un habla transparente, intercambiable, lenguaje puro y transferible entre dos o más seres dispuestos a un diálogo en el cual ellos mismos se convertirían en transparencia y maravillosa claridad. Ahora bien, con Nietzsche, el problema es muy distinto. Lo que alcanzamos es el fin del monotonoteísmo, la caída de los dioses, la destrucción de la metafísica, pero el paso siguiente, el paso (no) más allá de la tradición, es uno condenado al eterno retorno, al infinito vagar por desiertos

1 Por supuesto que no intentamos aquí un análisis último de la argumentación aristotélica, sino que proponemos una lectura que destaque la importancia del lugar ocupado por el diálogo en dicha reflexión. Vale mencionar aquí que Derrida relaciona al silencio con la temática de la alteridad, volviéndose para nosotros un anticipo de nuestro trabajo. "La ausencia, o el alejamiento, es para él [Aristóteles] sinónimo de silencio: los amigos están separados cuando no pueden hablarse. [Se trata de] algo que para él va junto con la separación topológica, a saber, la imposibilidad de la alocución o del coloquio" (Derrida 1998, p. 250).

2 Sobre esta interpretación de la voluntad de poder nietzscheana, véase Cragnolini 1995. 
inhóspitos para todo ser humano. Si ya no existe un lenguaje que pueda alcanzar una verdad, si el mundo es eso otro que siempre escapa al impulso momificador del concepto, a su intento de reducirlo siempre a lo mismo; la cuestión es cómo y para qué hacer filosofía. Es decir, sin un fundamento último sobre el que apoyar nuestros temblorosos pies, el salto más allá tampoco es posible, y el temor ante el abismo nos impide una danza alegre propia del filósofo artista.

Y aquí irrumpe el pensamiento de Maurice Blanchot, quien responde a esta cuestión al decir que

[...] hablar -esto se sabe hoy en día- es poner en juego semejante falta [i.e. la falta del sentido único], mantenerla y profundizarla para disponer de ella; pero profundizarla, también es hacer que sea siempre mayor y finalmente es ponernos, en la boca y bajo la mano, ya no la pura ausencia de los signos, sino la prolijidad de una ausencia indefinida e indiferentemente significante: designación que, incluso si lleva la nulidad, es imposible de anular. Si no fuese así, hace mucho que el silencio nos habría satisfecho a todos. Pero precisamente el silencio -la falta de signos- siempre es significante y siempre de más en relación con la falta ambigua que está en juego en el habla (Blanchot 1970, p. 521).

El silencio no es suficiente, ya que se vuelve una confirmación de la lógica aristotélica. Por ello, debemos hablar teniendo presente la ausencia de sentido, volviéndola significante y, así, superando la oposición habla-silencio, dar lugar a otra lógica, siempre por venir. Reconocer órdenes fugaces, construidos sobre ficciones útiles momentáneas, que posibilitan la vida y el tránsito por sobre el abismo; ésta es nuestra tarea.

Finalmente, al concebir el presente trabajo nos encontramos con otro nombre que alberga este camino a través del desierto, Franz Kafka, en uno de cuyos cuentos leemos:

[...] al hablar no somos completamente independientes desde el momento que no podemos alcanzar la verdad ni objetivo alguno, sino que solamente nos son asequibles el chiste y la diversión (Kafka 2003a, p. 315).

Los siguientes capítulos han sido recortes arbitrarios y sin aires de exhaustividad, en los que se intentará abordar distintas perspectivas que nacen con la crisis del lenguaje representativo, pero que en última instancia deben reflejar un trasfondo común. Señalaremos algunos puntos de la obra de Kafka que encontramos en directa relación con las propuestas de la filosofía nietzscheana y que atraviesan el pensamiento del genial filósofo francés. Blanchot lleva a un extremo la posibilidad misma de la escritura después de la filosofía del martillo, justamente reflexionando y hablando alrededor de un secreto, de un punto innombrable abandonado al silencio y al olvido, abriendo así la posibilidad del porvenir. 


\section{El corazón secreto del silencio}

Nietzsche afirma que el lenguaje ejerce sobre la realidad una violencia propia de todo intento de reducir lo otro a lo mismo, es decir, de apresar por medio de conceptos el devenir del mundo, momificar lo diverso reuniéndolo bajo un único rótulo. Por lo tanto, todo decir acerca de la realidad debe ser considerado una interpretación, una perspectiva lanzada sobre la misma, que en última instancia la constituye. Leemos en uno de sus fragmentos póstumos: "no hay ningún estado de hecho, todo es fluido, inaprensible, huidizo; lo más duradero todavía son nuestras opiniones" (Nietzsche 1998, p. 27). De aquí se sigue fácilmente la crítica al llamado monotonoteísmo.

El mundo ficticio del sujeto, de la substancia, de la <razón>, etc. es necesario: hay en nosotros un poder que ordena, simplifica, falsifica, separa artificialmente. $<$ Verdad $>$ : voluntad de hacerse dueño de la multiplicidad de sensaciones, ensartar los fenómenos bajo categorías determinadas (Nietzsche 1998, p. 74).

Si éste es el carácter necesario de todo lenguaje, el problema de uno más cercano a la verdad, como tal vez pueda leerse en El nacimiento de la tragedia, ya queda descartado y surge principalmente el problema gnoseológico-ético: ¿cómo relacionarse con lo otro sin ejercer una violencia determinada sobre éste?, ¿cómo acceder a lo oscuro en su propia oscuridad, sin forzarlo, sin calificarlo, sin determinarlo?, ¿cómo hablar del secreto dejándolo ser aún secreto? De esta cuestión depende la posibilidad de la misma filosofía.

Blanchot intenta responder a esta pregunta al sostener que el lenguaje del secreto es un lenguaje silencioso: la literatura. Éste es un lenguaje del no-poder, es decir, deja de ser una violencia ejercida sobre lo otro, en tanto ya no se da una presencia por detrás que velaría por su propio discurso ${ }^{3}$. En él, el silencio se habla; es un lenguaje sin sentido, errante, que "designa el afuera infinitamente distendido que tiene lugar en la intimidad de la palabra [...] Sólo que, aquí, el afuera es vacío" (Blanchot 1969a, p. 45). De este modo, distingue Blanchot la palabra-útil de la literatura, afirmando que

3 Aquí encontramos la principal diferencia con la obra de Lévinas, ya que Blanchot le critica que el privilegio, para el hombre que está hablando, de poder auxiliar a su habla, pertenece igualmente al Otro y al Ego y los hace así iguales, reduciéndolos bajo el concepto "subjetividad". "Un pensamiento que reconoce al Otro esta dimensión de exterioridad radical en relación con el Ego, no podría a la vez pedir a la interioridad que le suministrara un denominador común entre el Ego y el Otro, ni tampoco que buscara en la presencia (subjetiva) del $<$ Yo $>$ junto a su habla lo que haría del lenguaje una manifestación sin par [...]" (Blanchot 1970, p. 108). 
[...] aquí se reconoce el $<$ salto $>$ que es la literatura. Disponemos de un lenguaje común y éste hace disponible lo real, dice las cosas, nos las da apartándolas, y él mismo desaparece en este uso, siempre nulo e inaparente. Pero, al convertirse en lenguaje de <ficción>, éste se vuelve fuera de uso, inusitado; y, sin duda, lo que designa creemos recibirlo todavía como en la vida corriente, e incluso más fácilmente, $[\ldots]$ a condición de que se haya derrumbado primero el mundo en donde sólo nos es dado usar las cosas, a condición de que las cosas se hayan alejado infinitamente de sí mismas y hayan vuelto a ser la indisponible lejanía de la imagen; a condición, también, de que ya no sea yo mismo y de que ya no pueda decir yo (Blanchot 1969b, p. 233).

En otras palabras, el lenguaje intercambiable como un bien de uso, tal como lo veía Aristóteles, debe ser dejado de lado a la hora de hablar de literatura. El lenguaje propio de esta última es aquél que sobrevive a la muerte de todos los dioses, a la caída del último de los fundamentos, y que por ello mismo no dice nada, no refiere a nada, sino solo a sí mismo. Pero también destaca esa misma nada como una nada presente, un abismo que se abriría ante los ojos curiosos de aquél que buscase develar un secreto, sin saber que lo propio del secreto es el desconocimiento de su existencia.

El lenguaje, en el mundo, es, por excelencia, poder. El que habla es el poderoso y el violento. Nombrar es esta violencia que aparta lo que está nombrando para tenerlo bajo la forma cómoda de un nombre. [...] Por lo tanto, es necesario rescatar en la obra literaria el lugar donde el lenguaje sigue siendo relación pura, ajena a cualquier dominio y a cualquier servidumbre, lenguaje que también habla sólo a quien no habla para tener ni para poder, ni para saber ni para poseer, ni para convertirse en maestro y amaestrarse, es decir, sólo a un hombre muy poco hombre (Blanchot 1969b, pp. 40-41).

Por otro lado, Blanchot sostiene que el escritor permanece en el silencio, y así "se preserva en el interior de la obra, está contenido allí donde no hay nada contenido" (Blanchot 1969a, p. 21). Por esto mismo Zaratustra desea ser perdido, abandonado bajo la furia desastrosa del olvido, para así morar en el silencio, innombrado. Nietzsche reconoce la imposibilidad de un más allá de la ley aristotélica, la cual prescribe que salir a la luz es imposible sin caer bajo el influjo del carácter metafísico del lenguaje. En sus escritos leemos:

[...] sólo pensamos dentro de la forma del lenguaje [...] Dejamos de pensar si no queremos hacerlo en la coacción del lenguaje, precisamente por ello todavía llegamos a la duda, al ver aquí un límite como límite. El pensar racional es un interpretar según un esquema que no podemos rechazar (Nietzsche 1998, p. 40).

Si el lenguaje es el límite de nuestro pensar, el poner de relieve este límite, inevitablemente a partir del interior del mismo, es hacer caer todas las "verdades" de la tradición (inclusive al "hombre"), para así plegar el pensamiento sobre sí mismo y, transgrediendo esos límites, pensar otras maneras de pensar. Más allá del carácter metafísico del lenguaje, surge el otro, lo incógnito, lo oscuro, como aquello que no puede ser abordado por nuestro obrar, secreto ante el cual todo intento de acercarme implica una violencia que borra su singularidad. 
La $<$ comunicación $>$, para volver a un término fuera de lugar, puesto que ya no hay medida común, la comunicación tan sólo es cuando escapa al poder y cuando se anuncia en ella la imposibilidad, nuestra última dimensión (Blanchot 1970, p. 93).

Por lo dicho hasta aquí, Blanchot debe reconocer la ausencia del libro, es decir, el fin de la representación de la literatura y del arte en general como una conversación, un intercambio, en el cual el libro se convertiría en un bien de uso, portador de un mensaje listo para ser recibido por el mejor postor.

La escritura que, por su propia fuerza liberada lentamente -fuerza aleatoria de ausencia-, parece dedicarse únicamente a sí misma y queda sin identidad, señalando poco a poco posibilidades muy distintas, esto es, una manera anónima, distraída, diferida y dispersa de estar en relación, con lo cual todo está implicado, empezando por la idea de Dios, del Yo, del Sujeto, y luego de la Verdad, y terminando por la idea del Libro y de la Obra, de suerte que esta escritura (considerada en su rigor enigmático), lejos de aspirar al Libro, más bien marcaría su fin: escritura que podría considerarse fuera del discurso, fuera del lenguaje [...] el libro indica siempre un orden sometido a la unidad, un sistema de nociones en que se afirma la primacía de la palabra sobre la escritura, del pensamiento sobre el lenguaje, y la promesa de una comunicación que sería algún día inmediata y transparente [...] escribir es la violencia más grande porque transgrede la ley, toda ley y su propia ley (Blanchot 1970, pp. 10-11).

Esta ley transgredida es la aristotélica, la del principio de no-contradicción, la garante del diálogo, la comunicación y el poder. Este modelo de escritura, en tanto más allá de la palabra-útil, es también el más allá de la lógica, pero necesariamente debe reconocer el límite impuesto por ésta, en tanto es inherente al propio lenguaje.

En El espacio literario, Blanchot señala la estrecha relación que encuentra entre Kafka y Hoffmansthal (Blanchot 1969a, p. 173), enfrentándonos nuevamente con la pregunta sobre la posibilidad de la escritura cuando ya parece imposible deshacerse de la condena al silencio ${ }^{4}$. En Carta al padre encontramos una referencia a la ley, tal vez la aristotélica, y el límite infranqueable que la misma instaura.

La imposibilidad de una relación tranquila tuvo otra consecuencia, sin duda natural: perdí el hábito de hablar. Seguramente no habría llegado nunca a ser un gran orador, pero el lenguaje humano común y fluido habría podido dominarlo; pero ya muy temprano me prohibiste la palabra (Kafka 2003b, p. 44).

Sin embargo, la palabra aquí perdida es la del lenguaje cotidiano, cuya carencia tal vez posibilita esa otra habla, la escritura, en la que se da una forma de relación con lo otro que no violenta su misma separación. Kafka habla, sí, pero con esa habla de no-poder,

4 Un cuento dedicado casi en su totalidad al tema del silencio, pero que por una cuestión de espacio no analizaremos en el presente trabajo, es "Investigaciones de un perro" (Kafka 2003a, pp. 465-509). 
ociosa, que no quiere nada. Si el lenguaje muestra su carácter violento ante el devenir del mundo, el habla necesaria es aquella que se aleja de éste, que no intenta apresarlo en conceptos, habla inútil y desobrada. Al perder la posibilidad de comunicarse, de transmitir signos con un significado único, Kafka viola la ley, pero así renace en esa otra dimensión, la de la literatura, escritura sin referente, sin mundo, que solo dice la imposibilidad de sí misma.

Esta cercanía entre la escritura y el silencio se expresa en la obra de Kafka mediante los ruidos y gritos (por ejemplo, los de Josefine ${ }^{5}$, Gregorio ${ }^{6}$ o el canto-silencio de las sirenas) que están más allá del lenguaje y del mundo ${ }^{7}$. En El proceso es el propio Franz (uno de los encargados de la detención de K.) quien, al ser apaleado, profirió un grito que "no parecía proceder de un ser humano" (Kafka 1994a, p. 144). Al transgredir la ley, es el sin-sentido del mundo (i.e. el tribunal) el que se hace manifiesto, por lo que éste toma sus represalias, quitando la palabra y bloqueando todo diálogo posible. Algo similar sucede en El castillo, cuando K. decide telefonear a la alcaldía y del auricular sale un zumbido indeterminado, dejándolo sin habla (Kafka 1997, p. 26). El lugar de la ley es el silencio, origen de todo habla del mundo: "ahí arriba, en ese corredor, hay un silencio como uno ni imaginarse puede. Es tan silencioso eso que no se puede aguantar allí mucho tiempo. El silencio lo echa a uno" (Kafka 1997, p. 308).

La ley quita la palabra, y así sueña con conservar la lógica de su discurso. Sin embargo, el mismo tribunal muestra su incoherencia interna, es decir, la propia ley desnuda su secreto. Como afirma Blanchot, "para K., el proceso consiste en que la ley del discurso ha sido sustituida por una Ley Distinta, ajena a las reglas y en especial a la regla de no contradicción" (Blanchot 1969b, p. 175). Al hablar con el pintor Titorelli sobre los tres tipos posibles de absolución, K. señala lo contradictorio del tribunal, a lo que el otro agrega que no es un problema formal, sino que la diferencia radica entre lo que dice la ley y su experiencia personal. De este modo, nos permite inferir que el principio de no-contradicción, la univocidad del sentido de todo signo, es algo ajeno a la vida (Kafka 1994a, p. 206). Más adelante, ya en conversación con el sacerdote, y tras haberle éste relatado a K. el cuento Ante la ley, señala: "los intérpretes dicen: $<\mathrm{La}$ comprensión acertada de un asunto y la comprensión desacertada del mismo asunto no se excluyen completamente>" (Kafka 1994a, p. 265). La discusión finaliza con el sacerdote afirmando que hay que considerar todo lo proveniente de la ley no como cierto, pero sí como necesario, a lo que K. responde: "La mentira se convierte en el orden universal" (Kafka 1994a, p. 269). En El castillo se repite esta figura, ahora en boca de una mesonera:

“Josefine está casi más allá de las leyes” (Kafka 2003a, p. 245).

"Sus palabras resultaban ininteligibles, aunque a él le parecían muy claras, más claras que antes" (Kafka 2003, p. 90).

Cf. el excelente libro de Deleuze y Guattari (1978, pp. 13-15), en el que se relaciona esta pura materia sonora con la desterritorialización, es decir, el más allá del imperio de lo significante. 
[...] no tiene la menor esperanza de ser recibido por Klamm. Bien; si no hay entonces ninguna esperanza, tampoco la habrá por medio de este expediente. ¿Puede haber algo más claro? Además, digo que este expediente es el único verdadero enlace que puede tener con Klamm (Kafka 1997, p. 119).

El acceso al mundo está prohibido para el lenguaje del mundo, ya que aquél escapa al egipticismo del concepto; sin embargo, parece imposible ingresar de otro modo, volviéndose necesario pensar un no-acceso, un diferir infinito de la comunicación, que se separa del silencio y se vuelve literatura.

\section{II}

\section{La visión de la oscuridad}

Como corolario de lo analizado en el apartado anterior y oponiéndose a toda la tradición filosófica, en especial a Heidegger, Blanchot afirma que "hablar no es ver" (Blanchot 1970, p. 108). El habla es una forma de acceso a lo oscuro en su propia oscuridad, donde ya no hay una voluntad de dominio, una violencia, sino un girar en torno al Otro, para en este envolver destacar el centro incógnito eternamente oculto a la visión iluminadora. "Ver sólo supone una separación medida y medible: ver, sin duda, siempre es ver a distancia, pero dejando que la distancia nos devuelva lo que nos quita" (Blanchot 1970, p. 63); mientras que "el habla (al menos aquella a la que intentamos acercarnos: la escritura) pone al desnudo, sin retirar siquiera el velo y a veces incluso (peligrosamente) volviendo a velar -de un modo que no cubre ni descubre" (Blanchot 1970, p. 67). De manera similar a como el silencio se oponía a la palabra transparente, la oscuridad es la consecuencia necesaria para aquél que sueña con un más allá de la luz. Por lo tanto, el habla (i.e. la escritura o la literatura) es la revelación del otro en tanto Misterio y Enigma. Y aquí nuevamente la transgresión de una ley:

Cuando miramos lo que está delante de nosotros no vemos lo que está detrás. Cuando estamos aquí, es a condición de renunciar a allá: el límite nos mantiene, nos retiene, nos empuja hacia lo que somos, nos vuelve hacia nosotros, nos aparta de lo otro, hace de nosotros seres apartados. Acceder al otro lado sería entonces entrar en la libertad de lo que no tiene límites (Blanchot 1969a, p. 124).

Y ese acceso está dado por la literatura, ya que por ésta "estamos orientados hacia otra relación que no sería de poder ni de comprensión, ni de revelación siquiera, relación con lo oscuro y con lo desconocido" (Blanchot 1970, p. 93). Más allá del modelo de la visión, propio de una voluntad de saber que sueña con apropiarse del objeto hacia el cual dirige su intencionalidad, nos encontramos con el espacio infinito abierto por la escritura, aquél que se encuentra en los trasfondos del mundo y de la luz, pero que siempre nos revela la imposibilidad de mantenernos en él, ya que ese paso es un paso 
(no) más allá. En otras palabras, si transgredimos la ley aristotélica, al igual que para Edipo, el castigo es la ceguera. Sin embargo, el mundo de la oscuridad no se reduce a una nada eterna, y da lugar al surgimiento del otro; como si para poder ver más allá debiéramos cerrar nuestros ojos, suspender nuestra relación inmediata con el mundo, y así dejar de lado toda voluntad de dominio y apropiación.

En Kafka encontramos este tema en muchos de sus escritos, pero es en Ante la ley donde se manifiesta la metáfora de la luz en toda su magnitud, ya que el interior de la ley permanece finalmente inmune al poder de la visión. El campesino llega hasta las puertas de aquélla, las cuales se encuentran abiertas, y a pesar de que nada pareciera impedirle pasar a través de las mismas, desde ahí mismo intenta tímidamente mirar hacia adentro. Por parte del guardián, él mismo afirma no poder soportar la vista del tercer guardián, y uno podría aventurar que ni siquiera la del segundo, ya que se encuentra en la misma situación que el pobre campesino. Este último dedica el resto de sus días a mirar "casi ininterrumpidamente al guardián", perfeccionando su mirada inquisitiva, hasta el punto de llegar a distinguir "los piojos que tiene en su cuello de piel". Pero recién cuando, cercano a la muerte, "empieza a perder la vista y no sabe si realmente se está poniendo más oscuro a su alrededor o es solamente que sus ojos lo engañan", distingue un resplandor que sale por la puerta de la ley (Kafka 2003a, pp. 178-179). Es decir, mientras permanece con vida el campesino cree poder acceder al corazón de la ley perfeccionando y agudizando su ojo, mientras que es finalmente cuando su relación con el mundo-útil se ve interrumpida que logra acceder a ese otro ámbito, que es también el de la escritura. Leemos en otro relato:

Nunca estuve convencido por mí mismo de que yo existiese. Es que la imagen que me hago de las cosas que me rodean es tan inconsistente, que siempre tengo la impresión de que esas cosas deben haber vivido alguna vez pero que ahora están desapareciendo. Siempre, querido señor, tengo deseos de ver las cosas tal como son antes de que se me muestren (Kafka 2003a, p. 259).

El mundo de la utilidad, de la ley paterna, de la comunidad, es para Kafka aquél dominado por la vista. Así, reconociendo que para poder escribir debe dejarlo de lado, opta por la ceguera, por el encierro, soñando con un más allá de pura literatura, y sabiéndose al mismo tiempo atrapado en lo luminoso del día.

III

\section{La soledad necesaria}

Al afirmar que el paso por la escritura es la puesta entre paréntesis del mundo cotidiano, debemos reconocer que el espacio abierto por este gesto se vuelve un ámbito desierto. Es decir, si el mundo que me rodea se disemina ante mis impotentes ojos, con él se borrarán también los otros individuos y mi propio “yo". Por esta razón, 
en el primer capítulo de El espacio literario Blanchot se ocupa de lo que él llama la soledad esencial.

La soledad que alcanza al escritor mediante la obra se revela en que ahora escribir es lo interminable, lo incesante. El escritor ya no pertenece al dominio magistral donde expresarse significa expresar la exactitud y la certeza de las cosas y de los valores según el sentido de sus límites. Lo que se escribe entrega a quien debe escribir a una afirmación sobre la que no tiene autoridad, que es inconsistente, que no afirma nada, que no es el reposo, la dignidad del silencio, porque es lo que aún habla cuando todo ha sido dicho, lo que no precede a la palabra, porque más bien le impide ser palabra que comienza, porque le retira el derecho y el poder de interrumpirse [...] Kafka señala con sorpresa, con un placer encantado, que se inició en la literatura cuando pudo sustituir el "El" al "Yo". [...] El escritor pertenece a un lenguaje que nadie habla, que no se dirige a nadie, que no tiene centro, que no revela nada. [...] Allí donde está, sólo habla el ser, lo que significa que la palabra ya no habla, pero es, se consagra a la pura pasividad del ser (Blanchot 1969a, p. 20).

Encontramos aquí una posición radicalmente opuesta a la aristotélica. La literatura es el fin de todo diálogo posible, entendido como intercambio de signos-útiles, es la caída en el abismo de la absoluta soledad, solo que en éste, donde el mundo se me escapa, donde ya no soy un poder ante lo radicalmente otro, aún queda un resto, algo que hace posible el habla plural. Ese resto es para Blanchot lo impersonal, que reemplaza a la subjetividad ya aniquilada junto a todos los dioses de la tradición. "El $<\mathrm{El}>$ que se sustituye al $\langle$ Yo $>$, ésa es la soledad que alcanza al escritor por medio de la obra" (Blanchot 1969a, p. 22). El autor muere con la escritura, se vuelve un fantasma ante un habla que ya no es suya, que a partir del último trazo sobre una página ha sido condenada a vagar por el desierto de la iteración infinita. Sin embargo, en esta habla se da todavía una forma de relación social. "Alguien es lo que todavía está presente cuando no hay nadie. Allí donde estoy solo, no estoy, no hay nadie, pero está lo impersonal: el afuera como lo que previene, precede y disuelve toda posibilidad de relación personal. Alguien es el "El" sin rostro" (Blanchot 1969a, p. 25). Y este "El, pero en la medida en que la tercera persona no es una tercera persona y pone en juego lo neutro", es lo otro (Blanchot 1970, p. 128). Para decirlo en otras palabras, incluso en mi soledad más íntima, en mi ausencia de mundo brindada por la literatura, me reconozco atravesado por la alteridad de una forma absoluta.

Como ya hemos mencionado, en esta soledad esencial el mundo también se disuelve en sueños nocturnos y es por ello que el escritor se encuentra en constante tensión, al igual que el lenguaje, entre un mundo dominado por la utilidad y el "mundo" de la literatura, en el cual lo ocioso, el gasto, el derroche, son los principios dominantes (Bataille 2003, pp.110-135). Ya hablando de Kafka, Blanchot afirma que

[...] necesitaría más tiempo, pero también menos mundo [...] Pero si Kafka abandona la felicidad terrestre de una vida normal, abandona también la firmeza de una vida justa, se pone fuera de la ley, se priva del suelo y del asiento que necesita para ser y, en cierta medida, priva de ello a la ley (Blanchot 1969a, p. 55). 
De esta manera, se comprende todo el sufrimiento de Kafka, o de todo escritor, por saberse fuera de la ley, fuera del mundo, pero necesariamente apresado por éstos. Y no es esta prisión diferente a la mencionada anteriormente, la sostenida por el lenguaje útil o el dominio de la luz, en la que necesariamente nos sumergimos en la vida cotidiana, donde el poder es la moneda corriente.

Si dejamos de lado la obra "literaria" de Kafka, vemos en sus diarios proyectada en toda su crudeza esta oposición entre el mundo cotidiano por un lado y la literatura por el otro. Allí leemos: "26 de diciembre. Hace dos días y medio que, aunque no del todo, estoy solo y, si no me he transformado ya, voy en camino de hacerlo. La soledad tiene sobre mí un poder que nunca falla. Mi interior se diluye (por el momento sólo superficialmente) y está dispuesta a dar salida a lo profundo" (Kafka 1995, p. 19). Esta soledad sabe Kafka que es aquélla solicitada por la literatura, y a la hora de pensar en la posibilidad del matrimonio, con sus consecuencias necesarias principalmente en cuanto a lo laboral, no duda en descartarla ante la perspectiva de tener que abandonar la escritura ${ }^{8}$. Arraigarse en el mundo implicaría una pérdida insoportable, por lo que decide escribir al padre de Felice una carta con motivo de su reciente compromiso con ella, que contiene un pasaje esclarecedor:

Mi empleo me resulta insoportable, porque contradice mi único anhelo y mi única profesión, que es la literatura. Puesto que no soy otra cosa que literatura, y no puedo ni quiero ser otra cosa, mi empleo no podrá nunca atraerme, pudiendo en cambio destrozarme totalmente. No estoy muy lejos de esta situación. [...] [su hija] conmigo debe ser desgraciada, por lo que a mí se me alcanza. No sólo por mis circunstancias externas, sino mucho más por mi propia manera de ser; soy una persona reservada, silenciosa, insociable, insatisfecha, sin que pueda definirlo para mí como una desgracia, puesto que sólo se trata del reflejo de mis objetivos (Kafka 1995, p. 199).

Si debe abandonar el imperio de la ley (la aristotélica y la del mundo-útil) para poder dedicarse a la literatura, qué mejor que apelar a ella (al padre) para que por nuestra falta nos expulse de su dominio.

Ahora bien, lo que se pregunta Blanchot es: ¿por qué sostener, a pesar de lo dicho hasta aquí, la escritura de un diario? A lo que Kafka responde: " 16 de diciembre. No volveré a abandonar este diario. Debo mantenerme aferrado a él, porque no puedo aferrarme a otra cosa" (Kafka 1995, p. 19). Es decir, el diario se vuelve el único lazo con el mundo cotidiano, con la comunidad de los hombres, cuando se disuelve el "yo" del escritor en la letra que derrama sobre el papel. Sin embargo, Blanchot señala la contradicción existente a la hora de ser la escritura misma quien nos salvaría de un estado de pérdida absoluto:

8 En un apartado titulado "Recopilación de todo lo que se puede decir a favor y en contra de mi matrimonio" leemos: "3. Necesito estar solo mucho tiempo. Lo que he realizado hasta ahora no es más que un triunfo de la soledad. 4. Odio todo lo que no tiene relación con la literatura"(Kafka 1995, p. 195). 
[...] a partir del momento en que la obra se convierte en búsqueda del arte, en literatura, el escritor siente cada vez más la necesidad de conservar relación consigo [...] El Diario es un Memorial. ¿Qué debe recordar el escritor? Debe recordarse a sí mismo, al que es cuando no escribe, cuando vive la vida cotidiana, cuando está vivo y verdadero y no moribundo y sin verdad. Pero el medio que utiliza para recordarse a sí mismo es, cosa extraña, el elemento mismo del olvido: escribir (Blanchot 1969a, p. 22).

Escritura y mundo de la vida cotidiana parecen irreconciliables, tal vez por una diferencia esencial de lógicas y de maneras de relacionarse con lo otro.

Hay, en el diario, como la feliz compensación, una por otra, de una doble nulidad. El que no hace nada con su vida escribe que no hace nada, y he aquí, sin embargo, algo realizado. El que se deja apartar de la escritura por las futilidades del día, vuelve a esas futilidades para contarlas, denunciarlas o complacerse en ellas, y he aquí un día repleto. [...] Uno escribe para salvar los días, pero confía su salvación a la escritura que altera el día (Blanchot 1969b, pp. 209-210).

La literatura parece oponerse al mundo y su lógica, por eso Kafka rechaza la institución familiar, siempre ligada a la esfera económica (Deleuze y Guattari 1978), al privilegiar su escritura por sobre todas las cosas. Sin embargo, dicho desarraigo parece no realizarse en su totalidad, ya que el paso más allá es siempre la nueva instauración del límite 9 . Tal vez Blanchot haya extremado dicha posibilidad, en un retiro solitario, más allá del mundo, pero sin por eso perder la compañía del otro.

IV

Vivir en el exilio, el errar infinito

Sin el suelo que sustenta nuestras palabras, sin ese fundamento que da firmeza a nuestros pasos al andar, sin ese hogar seguro al que siempre podemos retornar, lo que permanece aún es el errar, el andar con pies ligeros por el desierto. Por esto, escuchamos a Zaratustra decir: "no he encontrado hogar en ningún sitio: un nómada soy yo en todas las ciudades, y una despedida junto a todas las puertas" (Nietzsche 1998, p. 184). Y este movimiento de constante exilio tal vez haya sido el vivido por Kafka, ya que él

9 "Yo había sido contratado acá como agrimensor, pero sólo en apariencia. Jugaban conmigo. ¡Pero cómo se ha complicado esto! En cierto sentido he adquirido más importancia, y esto ya es algo. Ya tengo, por poco importante que parezca, un hogar, un puesto y un trabajo real. Tengo una novia, que cuando ando en otros menesteres se hace cargo de mis tareas profesionales. Me casaré con ella y me convertiré en miembro de la comunidad" (Kafka 1997, p. 204). 
era un checo judío que hablaba alemán, características éstas que parecían excluirlo de cualquier comunidad (Kafka 1994a, p. 15). En palabras de Blanchot,

[...] para Kafka, estar excluido del mundo quiere decir excluido de Canaán, errar en el desierto, y es esta situación la que hace su lucha patética y su esperanza desesperada, como si arrojado fuera del mundo, en el error de la migración infinita, tuviera que luchar incesantemente para hacer de ese afuera otro mundo, y de este error, el principio, el origen de una nueva libertad (Blanchot 1969a, p. 64).

En su análisis del "ser judío", Blanchot nos dice que "el judío es malestar y desgracia [...] El judío, a través de los tiempos, es el oprimido y el acusado. Es, ha sido el oprimido de cualquier sociedad. [...] ser judío sería desde un principio estar privado de las posibilidades principales de vivir" (Blanchot 1970, pp. 211-212). Pasternak da una respuesta en tres términos a la pregunta sobre el por qué de la existencia del ser judío, que Blanchot retoma:

[...] existe para que exista la idea de éxodo y la idea de destierro como movimiento justo; existe, a través del destierro y por la iniciativa que es el éxodo, para que la experiencia de lo extraño se afirme ante nosotros en una relación irreductible; existe para que, por la autoridad de esta experiencia aprendamos a hablar (Blanchot 1970, p. 214).

En este momento nos centramos sobre la primera característica, que Blanchot llama también la "verdad nómada" 10 , exigencia de arrancamiento, de salir, ir afuera, manteniendo así la posibilidad de una relación de justicia con ese otro extraño, entendida en términos levinasianos ${ }^{11}$.

Hay una verdad del destierro, hay una vocación del destierro, y ser judío consiste en estar condenado a la dispersión, porque la dispersión, lo mismo que incita a una residencia sin lugar, lo mismo que arruina toda relación fija entre el poder y un individuo, un grupo o un Estado, revela también, frente a la exigencia del Todo, otra exigencia, y finalmente impide la tentación de la Unidad-Identidad (Blanchot 1970, p. 214).

10 Opuesta al paganismo. "Ser pagano es fijarse, plantarse en tierra en cierto modo, establecerse mediante un pacto con la permanencia que autoriza la estadía y certifica la certidumbre del suelo. El nomadismo responde a una relación que no satisface la posesión" (Blanchot 1970, p. 214).

11 El extranjero está fuera del hogar, de la justicia y de un lenguaje común, pero paradójicamente solo está presente mediante su habla. A partir de aquí, aunque en realidad esta exigencia ya asedia todo nuestro trabajo, podríamos trabajar el problema de la alteridad tal como lo piensa Lévinas, pero por una cuestión de extensión nos limitamos a sugerirlo (Ver Blanchot 1970, p. 165). 
De aquí el movimiento paradójico kafkiano entre el sionismo y el anti-sionismo, paralelo a la exigencia de la obra y su pertenencia al mundo ${ }^{12}$. La pregunta que surge entonces es: ¿cómo dejar la seguridad del hogar y vivir siempre fuera, más allá de los límites, donde ya no soy un "yo" capaz de descansar en alguna posada sino que me encuentro siempre expuesto a la intemperie, al frío y a la constante búsqueda? Para dar respuesta a la misma, Blanchot sostiene que la errancia significaría una nueva relación con lo "verdadero", y este movimiento nómada se afirmaría "no como la eterna privación de una morada, sino como una manera auténtica de residir, como una residencia que no nos liga a la determinación de un lugar, ni al asentamiento junto a una realidad desde ya fundada, segura, permanente" (Blanchot 1970, p. 216). La verdad nómada es la que surge de la filosofía destructiva de Nietzsche. Ante el abismo, no más suelo fijo, sino una nueva verdad ficcional que nos permita incluir en sí misma su destrucción, y así llegar al eterno movimiento, el secreto del retorno.

Por el lado de Kafka, el tema del desierto, del espacio infinito, de las distancias insuperables tiene un lugar privilegiado. Ya sea a la hora de pensar en la posibilidad de ir siquiera al pueblo vecino más cercano (Kafka 2003a, p. 187) o recorriendo los pasillos infinitos del buque de América (Kafka 1998, p. 8), el errar en una búsqueda desesperada aparece una y otra vez a los ojos del lector. Sin embargo, es en sus dos principales novelas donde dicha cuestión se muestra en toda su dimensión. En El Castillo, K. es un forastero que no tiene lugar: "ya me siento un poco desamparado. Entre los campesinos no está mi lugar, pero tampoco en el castillo" (Kafka 1997, pp. 15-16). Cuando pregunta sobre la posibilidad de hablar con Klamm, un funcionario del castillo, se le responde: "usted no es del castillo; usted no es de la aldea. ¡Usted no es nada! Pero, lamentablemente, usted es algo, a pesar de todo: un forastero; uno que sobra y está de paso en todos lados" (Kafka 1997, p. 57). Todo el libro está dedicado al errar en busca del centro, del arraigo, aunque "caminaban, pero K. no sabía hacia dónde" (Kafka 1997, p. 35). Y en este deambular al desamparo de la ley se muestra el sin-sentido de la propia existencia: "usted ha sido contratado como agrimensor, pero, lamentablemente, no necesitamos agrimensor alguno" (Kafka 1997, p. 65). De manera similar, en El proceso, K. es un acusado vagando en búsqueda de su absolución, pero los tribunales son inaprensibles, infinitos, compuestos por una jerarquía que abarca todo, pero que a su vez se beneficia por la ignorancia, la falta de conocimiento acerca del centro (Kafka 1994a, pp. 168-182). Y esto es lo propio de la errancia, la infatigable búsqueda del centro, del secreto, que siempre es un girar en torno del mismo. Por eso, Blanchot nos dice que "lo esencial de la peregrinación de K. no consiste en ir de lugares en lugares, sino de exégesis en exégesis, de comentarista en comentarista" (Blanchot 1970, p. 604).

Ahora bien, podría uno preguntarse por qué este exilio, este estar fuera del hogar abre la posibilidad de una relación de justicia con el otro. Una posible respuesta es que

12 “Cómo - dice A. Neher- se puede estar a la vez en el Destierro y en el Reino, a la vez vagabundo e instalado? Precisamente, es esta contradicción la que hace del hombre judío un judío" (Blanchot 1970, p. 216). 
en el desierto, en la soledad esencial, el otro irrumpe, y en ese instante me descubro atravesado por la alteridad desde un tiempo inmemorial. Se vuelve imposible así anhelar una construcción que nos proteja de los enemigos exteriores e interiores (Kafka 2003a, p. 522), ya que ésta siempre estará sobre un desierto común, el desamparo que surge a partir del reconocimiento del lugar que ocupa el otro en lo más íntimo de nuestro hogar, asediado por espectros que exigen una respuesta y una responsabilidad absolutas. En su cuento Blumfeld, un solterón ya algo viejo, Kafka señala a la suciedad como algo intolerable para nuestro héroe, en un deseo de inmunidad ante la posible presencia de un otro contaminante de la pureza del sujeto. (Kafka 2003a, p. 369) A su vez, Blumfeld sueña con tener un animal que le haga compañía, pero que caiga bajo su poder, es decir, que sea previsible y controlable. Sin embargo, ya en lo íntimo de su hogar se encuentra con dos pelotas, que irrumpen y desterritorializan lo propio, la seguridad de la morada. Éstas extrañas invasoras se verán más tarde reflejadas en sus dos empleados, quienes se comportan de manera imprevisible incluso en el ámbito laboral. Esta misma irrupción se encuentra en Un médico rural, donde se afirma que "uno no sabe qué tiene en su propia casa" (Kafka 2003a, p. 169). Y de esta manera, fuera de la seguridad del hogar, fuera del mundo de la vida cotidiana, nos encontramos nuevamente con la literatura ${ }^{13}$.

La verdad de la literatura estaría en el error del infinito. [...] Para el hombre mesurado y de medida, el cuarto, el desierto y el mundo son lugares estrictamente determinados. Para el hombre desértico y laberíntico, expuesto al error de una tentativa necesariamente un poco más larga que su vida, el mismo espacio será verdaderamente infinito, aun cuando sepa que no lo es y tanto más cuanto que lo sabrá (Blanchot 1969b, p. 109).

El desierto es habitable, sí, pero siempre y cuando no olvidemos que el lenguaje es escritura, que no hay un sentido último sobre el que descansar. Andar cada día como la primera vez por el árido camino de la literatura, ese es nuestro infierno, pero también nuestro cielo.

Lo fragmentario, un diálogo inconcluso

Creemos que Kafka no puede ser posicionado entre las filas del surrealismo ${ }^{14}$, o si lo es, vale la aclaración que realiza Blanchot sobre este movimiento artístico (Blanchot 1970, p. 640). Kafka rompe la ley pero manteniéndose dentro de ella, reconociendo

13 Una interpretación del "paria" kafkiano que, sin estar en oposición directa a la nuestra, va por otro camino, se encuentra en Arendt 2004 (pp. 64-73 y 89-109).

14 Ésta es la interpretación de Orson Wells en su versión fílmica de "El proceso", que a pesar de su lectura en clave surrealista de Kafka, posee un valor inagotable. 
que no hay un más allá del mundo. Por su parte Blanchot llama a quien vive esta experiencia hombre trágico.

El hombre trágico es aquel para quien de repente se ha transformado la existencia: de claroscuro se ha vuelto tanto exigencia de claridad absoluta como encuentro de densas tinieblas, llamado a un habla verdadera y prueba de un espacio infinitamente silencioso $\mathrm{y}$, por último, presencia de un mundo incapaz de justicia que ofrece tan sólo la deserción de los compromisos, cuando se precisa lo absoluto y sólo lo absoluto, mundo inhabitable donde es necesario permanecer. Para el hombre trágico, en un instante todo se ha endurecido, todo es enfrentamiento de incompatibilidades (Blanchot 1970, p. 173).

Lo propio de este ser es el pensamiento trágico, y la forma que conviene a esta forma de pensamiento es paradójica y fragmentaria.

Paradójica: significa que siempre lleva hasta el extremo las afirmaciones contrarias que debe mantener juntas, aunque, sin poder evitar la paradoja, tampoco puede aceptarla, pues lo que busca es el cumplimiento de la síntesis que afirma absolutamente, pero como absolutamente ausente [...] El fragmento es la única forma de expresión que convenga a un trabajo paradojal (Blanchot 1970, p. 184).

Nuevamente nos enfrentamos a la discusión con el habla aristotélica.

Con Aristóteles, el lenguaje de la continuidad se convierte en lenguaje oficial de la filosofía, [...] esa continuidad es la de una coherencia lógica reducida a los tres principios de identidad, no-contradicción y tercero excluido (por consiguiente, coherencia con determinación simple) (Blanchot 1970, p. 32).

Tal aspiración a la continuidad absoluta corresponde al siguiente postulado: "la realidad misma -el fondo de las cosas, lo <cuanto es $>$ en su profundidad esencialsería absolutamente continua" (Blanchot 1970, p. 35). Por esto, ante una visión de la realidad como un constante devenir, un fluir eterno, incansable y desesperanzador para muchos, Blanchot reconoce la posibilidad del habla plural, que implica la exigencia de discontinuidad (Blanchot 1970, p. 32). "El habla como fragmento tiene relación con este hecho de que el hombre desaparezca" (Blanchot 1970, p. 258), que muera junto a sus dioses, y por lo tanto como unidad de lo Mismo, dejando lugar al habla del Afuera, la pluralidad, la diferencia no-reductible. Ahora bien, Blanchot señala también que el intervalo es necesario para toda habla, ya que sin silencio no se hablaría. "La interrupción es necesaria para cualquier serie de palabras. La intermitencia posibilita el devenir" (Blanchot 1970, p 136). De este modo, y siguiendo con la distinción entre dos tipos de experiencia de habla, la intermitencia se presenta según direcciones muy diferentes. Por una lado, el intervalo es el propio del habla cotidiana, del mundo, que tiende a la unidad del discurso. Es esencial, ya que permite el intercambio, pero remite en última instancia a un monólogo verdadero y continuo. Por otro lado, está la interrupción que introduce la "espera que mide la distancia entre dos interlocutores, ya no distancia reductible, sino irreductible” (Blanchot 1970, pp. 136-137). En este caso, la interrupción no está marcada por un silencio, sino por un cambio en la estructura del 
lenguaje, "cambio tal que hablar (escribir) es cesar de pensar sólo con miras a la unidad y hacer de las relaciones de palabras un campo esencialmente disimétrico que rige la discontinuidad" (Blanchot 1970, p. 138) ${ }^{15}$. Sin embargo, vale aclarar que la escritura fragmentaria no sería un acceso a lo "verdadero", sino un movimiento ligado al errar infinito, a la falta de un sentido último de las palabras. Si se rompe esta unidad esencial, con ella se disuelve el libro y la propia escritura homogénea y lineal.

Kafka nos habla con frecuencia de la construcción como un movimiento incesante, infinito e interrumpido. Su propia obra mantiene dicho movimiento y la inconclusión final. Leemos en sus diarios:

[...] es seguro que todo lo que he ideado anticipadamente, con buen ánimo, palabra por palabra, o bien de un modo incidental pero con palabras precisas, al intentar trascribirlo en mi escritorio, queda seco, alterado, inmovilizado, molesto para cuanto me rodea, temeroso, pero sobre todo fragmentario (Kafka 1995, p. 101).

Y el problema es la falta de tiempo, nuestra vida finita, que desde un pasado pre-histórico nos ha condenado al movimiento de la inconclusión (Bataille 1959, p. 186). El mundo de la acción, regido por un fin asequible, es ajeno a la literatura. Ya sea la muralla china o el refugio de una bestia, nunca alcanzamos la totalidad, el cierre sobre sí, sino que algo resta. Así toda (des)obra sigue necesariamente el sistema de construcción por partes, y con éste, pospone su finalización por toda la eternidad (Kafka 2003a, p. 405) En palabras de Blanchot:

Kafka, tal vez a pesar suyo, sintió profundamente que escribir es entregarse a lo incesante, y por angustia, angustia de la impaciencia, preocupación escrupulosa de la exigencia de escribir, se privó casi siempre de ese salto que permite la conclusión, esa confianza despreocupada y feliz por la cual (momentáneamente) se pone término a lo interminable (Blanchot 1969a, p. 74).

\section{La literatura y la muerte}

Más arriba hemos mencionado que si en la escritura el autor pierde su mundo, cayendo en el desierto infinito y abandonando para siempre la seguridad de su hogar, es porque él mismo desaparece como sujeto. En su obra, el autor de la misma muere, en cuanto ya no está presente para supervisar el destino de la misma. Sin embargo, la escritura

15 Vale mencionar que más adelante Blanchot introduce una nueva posibilidad, la interrupción hiperbólica, donde "se señala la desocupación, la < desobra> (quizás, el pensamiento)" (Blanchot 1970, p. 140). 
no puede darse de otra forma sino gracias a esta muerte prematura, si es que pretende ser escritura verdadera, es decir, habla sin poder. La escritura, por lo tanto, es al mismo tiempo concebida como relación con lo oscuro en tanto oscuro, experiencia que no confunde la obra con el libro y que reconoce la deconstrucción de la propia subjetividad en este proceso. Ya no soy un poder, sino solo relación que "afirma el abismo que hay entre $<$ ego $>$ y $<$ el otro $>$ y franquea lo infranqueable, pero sin abolirlo ni disminuirlo" (Blanchot 1970, p. 116). De esta manera, la muerte es la consecuencia para aquél que se entrega al juego del lenguaje sin voluntad de poder, y a ésta Blanchot la llama muerte contenta ${ }^{16}$. "Se aparta del mundo para escribir, y escribe para morir en paz. [...] La muerte, la muerte contenta, es el salario del arte. Es el objetivo y la justificación de la escritura. [Pero] sólo puede escribir quien es capaz de morir contento" (Blanchot 1969a, p. 85). Sin embargo, agrega Blanchot,"la capacidad de morir contento significa que la relación con el mundo normal ya está quebrada: de algún modo Kafka ya está muerto. Esto le ha sido dado, como el exilio, este don está ligado al de escribir" (Blanchot 1969a, p. 84).

Por otro lado, debemos señalar que esta muerte escapa también a mi voluntad de dominio, a la luz iluminadora que tranquilizaría nuestra espera. Querer dominar la muerte es una

[...] extraña empresa, contradictoria, esfuerzo por actuar donde reina la inmensa pasividad, exigencia que quiere mantener las reglas, impone la medida y fija un objetivo, en un movimiento que escapa de toda intención y de toda decisión. [...] Es notable que estos caracteres se apliquen también a otra experiencia, aparentemente menos peligrosa, pero tal vez no menos loca: la del artista. [Éste] está ligado a la obra de la misma extraña manera en que está ligado a la muerte el hombre que la toma como fin (Blanchot 1969a, p. 97).

Y esta experiencia, la de la literatura-muerte, se opone nuevamente a la del mundo cotidiano, donde la acción, la utilidad y el intercambio sellan el rumbo de nuestras vidas.

La conversión, este movimiento que conduce hacia lo más interior, obra donde nos transformamos, transformando todo, tiene algo que ver con nuestro fin, y esta transformación, esta realización de lo visible en lo invisible que es nuestra tarea, es la misma tarea de morir que nos ha sido hasta aquí tan difícil de reconocer, que es un trabajo, pero seguramente muy diferente del trabajo por el cual hacemos objetos y proyectamos resultados. [...] en el mundo, las cosas son transformadas en objetos a fin de apoderarse de ellas, utilizarlas, hacerlas más seguras en la firmeza visible de sus límites y la afirmación de un espacio homogéneo y divisible, pero en el espacio imaginario, son transformadas en lo inasible, fuera de uso y de la usura, no nuestra posesión sino el movimiento de la desposesión que nos despoja de ellas y de nosotros, no seguras (Blanchot 1969a, p. 131).

16 "[...] lo mejor que he escrito tiene su origen en esta capacidad de morir contento [...] me complace morir con el que muere" (Kafka 1995, pp. 280-281). 
Al igual que en El cazador Gracchus (Kafka 2003a, pp. 396-401), la imposibilidad de la muerte aparece repetidas veces en los Diarios. Allí leemos:

Morir no sería nada más que entregar una nada a la nada; pero esto sería imposible de concebir, porque cómo podría uno, no siendo más que una nada, entregarse de un modo consciente a la nada, y no sólo a una nada vacía, sino a una nada rugiente, cuya nulidad sólo consiste en su incomprensibilidad (Kafka 1995, p. 210).

La muerte es aquello más allá de mi comprensión, escapa a mi horizonte, abisma mi mundo-útil, al igual que la literatura. Ya no se trata entonces de la muerte como objeto a la mano, sino "del eterno suplicio del morir" (Kafka 1995, p. 264). Y en este punto, volviendo a destacar la imposibilidad del paso más allá, podemos pensar que Kafka soñara con la destrucción de su obra tras su muerte mundana, tal vez como último intento desesperado por no caer bajo el velo de la otra muerte, la abismal, inefable e inaprensible. Tal vez todavía se consideraba dueño de su obra, un poder ante la misma y previniendo toda posible violación de su soberanía, prefiriera su destrucción. Sin embargo, otro podría sugerir que al estar ya muerto, desligado del mundo cotidiano de la ley aristotélica, considerase superfluo ese eterno morir, y por lo tanto, ya no viera en su obra literaria un medio para romper el velo de lo mundano, sino un objeto más destinado para el consumo. De todas maneras, su (des)obra se manifiesta como tal, y sigue su rumbo de manera independiente del destino de un hombre, cuyo nombre comienza con esa inicial, impersonal y asesina.

IX

\section{Literatura y politica}

El largo recorrido que hemos seguido, desde la ley aristotélica hasta los distintos modos en que la ruptura con la misma se manifiesta en el ámbito de la escritura, tiene como corolario una dimensión política ${ }^{17}$. El habla aristotélica, con su transparencia y univocidad de sentido, lleva en última instancia a afirmar la supremacía del Estado por sobre toda posible voz que irrumpa en el ámbito de lo público. De aquí hasta Hegel, el modelo monológico prevalece. En éste, si hay diálogo es con vistas a fundar una unidad, un acuerdo, que siempre implica una violencia sobre el otro. Ahora bien, la literatura, en tanto habla de no-poder, nos permite acceder a otro modo de relación social, más allá de la lógica del intercambio moderna.

El arte, inútil al mundo para quien sólo cuenta lo que es eficaz, es aún inútil a sí mismo [...] Nada más importante que esta soberanía que es negación y que esta

17 Esta es la tesis de dos libros maravillosos, Bataille 1959 y Deleuze y Guattari 1978. 
negación que, por un cambio de signo, es también la afirmación más pródiga, el don, el don creador, lo que dispensa sin reserva y justificación, lo injustificado a partir de lo cual puede fundarse la justicia (Blanchot 1969a, p. 203).

Si con la escritura se desvanece el mundo-útil, se da lugar a la llegada de lo otro, del Otro y de otra política ${ }^{18}$. En palabras de Blanchot:

[...] la poesía sería el medio de la nueva esperanza. [...] Hay esperanza en cuanto ésta se refiere, lejos de cualquier aprehensión presente, de cualquier posesión inmediata, a lo que siempre vendrá -y tal vez no venga nunca-. [...] La esperanza dice la posibilidad de cuanto escapa a lo posible; ella es, en el límite, la relación recobrada, allí donde está perdida la relación. La esperanza es más profunda, cuando por sí misma se retira y se destituye de toda esperanza ostensible (Blanchot 1970, p. 83).

Y es esta esperanza la que le queda aún a Kafka (Kafka1995, p. 304), esperanza de lo por-venir, de lo imposible, de lo más allá de la ley y, junto a ella, la esperanza puesta en la literatura como otro modo de comunicación, y por qué no, de vida en comunidad.

Para finalizar, escuchemos a Blanchot:

[...] cuanto más se afirma el mundo como futuro y el pleno día de la verdad donde todo tendrá valor, donde todo tendrá sentido, donde el todo se realizará bajo el dominio del hombre y para su uso, más parece que el arte deba descender hacia ese punto donde nada aún tiene sentido, más importante se hace que mantenga el movimiento, la inseguridad y la desventura de lo que escapa de toda percepción y de todo fin. El artista y el poeta han recibido la misión de recordarnos obstinadamente el error, de orientarnos hacia ese espacio donde todo lo que nos proponemos, todo lo que hemos adquirido, todo lo que somos, todo lo que se abre sobre la tierra y el cielo, retorna a lo insignificante, donde lo que se aproxima es lo no-serio y lo no-verdadero, como si a lo mejor surgiese de allí la fuente de toda autenticidad (Blanchot 1969a, p. 236).

\section{Referencias bibliográficas}

Arendt, Hannah (2004), La tradición oculta, trad. R. S. Carbó y V. Gómez Ibáñez. Buenos Aires: Paidós.

Bataille, Georges (2003), La conjuración sagrada. Ensayos 1929-1939, trad. S. Mattoni. Buenos Aires: Adriana Hidalgo.

18 Desde ya que solo abrimos el espacio para una reflexión sobre la relación entre la literatura y la política, a la cual no le debe faltar una incursión por la obra de Lévinas y Derrida, entre otros. 
(1959), La literatura y el mal, trad. Lourdes Munárriz. Madrid: Taurus.

Blanchot, Maurice (1970), El diálogo inconcluso, trad. P. de Place. Caracas: Monte Ávila. Paidós.

(1969a), El espacio literario, trad. V. Palant y J. Jinkis. Buenos Aires: 1969.

(1969b), El libro qué vendrá, trad. P. de Place. Caracas: Monte Avila,

(1990), La escritura del desastre, trad. P. de Place. Caracas: Monte Avila. (1994), El paso (no) más allá, trad. C. de Peretti. Barcelona: Paidós. (1991), De Kafka a Kafka, trad. J. Ferreiro. México: FCE.

Cragnolini, Mónica B. (1995), "Nietzsche y el problema del lenguaje en la perspectiva de la música. Variaciones en torno a Doktor Faustus", Cuadernos de Filosofía (41): 91-118, Buenos Aires.

(2000), "La metáfora del caminante en Nietzsche. De Ulises al lector nómade de las múltiples máscaras", Ideas y valores, 114: 51-64. Bogotá: Universidad Nacional de Bogotá.

Deleuze, Gilles y Guattari, Félix (1978), Kafka, por una literatura menor, trad. J. Aguilar Mora. México: Era.

Derrida, Jacques (1998), "Firma, acontecimiento, contexto", Márgenes de la filosofía, trad. Carmen González Marín. Madrid: Cátedra, pp. 356-358.

Kafka, Franz (1994a), El proceso, trad. Isabel Hernández. Madrid: Cátedra. (1997), El castillo, trad. F. Zanutigh Núñez. Buenos Aires: Losada.

(1998), América, Losada, trad. F. Zanutigh Núñez. Buenos Aires: Losada. (2003a), Relatos completos, trad. F. Zanutigh Núñez. Buenos Aires: Losada.

(1995), Diarios (1910-1923), trad. F. Formosa. Barcelona: LumenTusquets.

(1981), Cartas a Mílena, trad. N. Mendilaharzu de Machain. Buenos Aires: Losada.

(2003b), Carta al padre, trad. Carlos Correas. Buenos Aires: Leviatán.

(1994b), La edificación de la muralla china y otros cuentos, trad. J. L. Borges. Buenos Aires. Losada.

Lévinas, Emmanuel (1974), Humanismo del otro hombre, trad. Daniel E. Guillot. México: Siglo XXI.

Nietzsche, Friedrich (1997), Más allá del bien y del mal, trad. Andrés Sánchez Pascual. Madrid: Alianza.

(1998), Asi habló Zaratustra, trad. A. Sánchez Pascual. Madrid: Alianza.

(1990), Sobre verdad y mentira en sentido extramoral, L. M. Valdés

Villanueva. Madrid: Tecnos. 
(1998), El nihilismo: escritos póstumos, trad. G. Mayos. Barcelona: Península.

Sánchez Meca, D. (1989), En torno al superhombre. Nietzsche y la crisis de la modernidad. Barcelona: Anthropos. 